\title{
La perspectiva cristológica en la renovación de la Teología Moral
}

\author{
José Manuel Martínez Guisasola \\ Centro de Estudios Teológicos de Sevilla
}

\begin{abstract}
Resumen: Desentrañar el misterio del Verbo Encarnado tiene que ser el estímulo de todo teólogo en su quehacer académico independientemente de cuál sea la rama de la teología en la que se circunscriba. La moral durante un larguísimo período de tiempo ha mantenido en el ostracismo el evento Cristo desencarnándose de una sana antropología que permitiera la confección de un marco teórico que sirviera como sostén de los postulados éticos que deben regir el perfeccionamiento en la vida del creyente. Lo que se pretende en este estudio es explicar los motivos por los cuales la teología moral ha adolecido de esto así como el proceso de renovación a través del cual la cristología se ha ido incluyendo en la reflexión de la ética cristiana.
\end{abstract}

\begin{abstract}
To disentangle the mystery of Incarnated Verbum should be the intrinsic driver of any Theology Academic in his daily activity, independently of his area of expertise within Theology. Moral has hidden the event of Christ during a very long time frame, forgetting am appropriate anthropology enabling the development of a theoretical framework giving support to the ethics of the daily activity for a believer. We pretend in this paper to explain the reasons why moral theology has lacked of such approach, as also to see the renewal being made, through which Christology has been introduced within the reflection about Christian Ethic.
\end{abstract}

\section{FACTORES QUE HAN PROVOCADO LA CRISIS EN LA TEOLOGÍA MORAL}

En el siglo $X X$, los moralistas han hecho un esfuerzo importante por renovar su disciplina, esfuerzo no siempre reconocido pues la actualización de la misma ha quedado un poco eclipsada en comparación con la renovación de los estudios bíblicos, patrísticos, litúrgicos, eclesiológicos, etc. De hecho el acontecimiento eclesial más importante del pasado siglo, como fue la celebración del concilio Vaticano II, no dedica ni un solo documento a la teología moral de modo 
exclusivo como sí hizo con las disciplinas anteriormente citadas. ${ }^{1}$ No obstante pensamos que a pesar de la falta de un documento magisterial el concilio recoge de modo transversal los esfuerzos que desde el siglo XVIII en adelante se ha hecho por darle a la moral un enfoque más cristológico intentando con ello rescatarla del positivismo jurídico en la que había sido encerrada.

A este respecto vamos a presentar aquellos factores que históricamente han ido originando una cierta crisis en la teología moral para poder comprender mejor las líneas trazadas para su renovación.

\subsection{El nominalismo}

El principal adalid de esta corriente filosófica fue Roscelino de Compiègne (1050-1120). Sus escritos no se conservan a excepción de una carta sobre la Trinidad. Todo lo que se conoce de su pensamiento es a partir de lo que sus adversarios, Abelardo y Anselmo de Canterbury, nos han transmitido. Según ellos, la postura filosófica de Roscelino consistía en una defensa a ultranza de la existencia de las cosas individuales cayendo de este modo en un particularismo en oposición a la existencia de los universales. ${ }^{2}$

Unos dos siglos después esta postura filosófica fue asumida, radicalizada y sobre todo propagada por Guillermo de Ockham. Para el monje franciscano inglés el universal simplemente no existe, es decir, no tiene correlato óntico. En este sentido, el auténtico conocimiento es sólo el de la cosa particular. A través de la experiencia de las cosas particulares extraemos nuestros conceptos universales. Los conceptos y las palabras, es decir, los nombres (de ahí nominalismo) representan las cosas particulares. ${ }^{3}$ Para Ockham, la verdadera realidad es la particular, la individual.

Pues bien, esta corriente de pensamiento difundida en los círculos intelectuales y académicos de la Europa del siglo XIV penetró sibilinamente en el desarrollo de la teología moral. Según el esquema nominalista lo importante en la vida moral son los actos individuales considerados aisladamente unos de otros y no el conjunto de los mismos que es lo que se proponía desde la corriente tomista, considerar las acciones humanas dentro de la noción de virtudes. Para el nominalismo, las virtudes serían algo ficticio al equipararlas a los universales, en cambio el acto concreto equivaldría a la cosa particular. De este modo el moralista ya no tendría la misión de estudiar la asunción y la vivencia de las virtudes

1 Si acudimos a los documentos del concilio podemos apreciar cómo no existe ninguno que de un modo único y singular esté destinado a la teología moral. En cambio existe una constitución dogmática orientada a subrayar la importancia de la Sagrada Escritura (Dei Verbum), otra sobre la renovación de la liturgia (Sacrosanctum Concilium), una tercera sobre la renovación eclesiológica (Lumen Gentium) fortalecida con una cuarta constitución dogmática (Gaudium et Spes) que versa sobre la relación de la Iglesia con el mundo actual.

Cf. J. FISCHL, Manual de Historia de la Filosofía, Herder, Barcelona 19947, 154-155.

3 Ibidem, 206-207. 
por parte del sujeto agente sino que tendría que diseccionar el comportamiento humano para llegar a las acciones individuales en el contexto específico en el que éstas han sido realizadas con la finalidad de estudiarlas caso por caso. ${ }^{4}$ En nuestra opinión, creemos que le debemos a la influencia del nominalismo la aparición del método casuístico que durante tanto tiempo ha marcado el discurrir teológico en el ámbito moral. ${ }^{5}$

Pero la impronta nominalista en nuestra disciplina no se circunscribe sólo y exclusivamente a lo que ya hemos expuesto sino que se deja apreciar también en la misma noción de bien y de mal. Para Ockham y, sobre todo, para los seguidores de Duns Scoto el bien y el mal no dependen de la naturaleza de las cosas sino de la voluntad divina. Es decir, una cosa es buena porque Dios ha decidido que sea buena y es mala porque Dios así lo ha querido. Pero pudo haber establecido lo contrario. Para un nominalista la mentira sería un pecado porque Dios así lo ha establecido pero no porque mentir esté mal en sí mismo. Desde este planteamiento se diluye la concepción de lo "intrínsecamente malo", postura defendida en la escolástica por Santo Tomás de Aquino.

Con esto se va perfilando la aparición de lo que se dio a conocer como positivismo jurídico divino, expresión con la que se quiere dar a entender que lo que es malo, lo es porque está prohibido y que no está prohibido porque sea malo, ya que Dios pudo haber decidido lo contrario. En este contexto ideológico se encasilló a la teología moral por eso no debe extrañarnos que bajo el prisma de esta premisa los moralistas volvieran su mirada no hacia la naturaleza misma de los actos humanos sino hacia los preceptos que expresan y manifiestan la voluntad de Dios. En este sentido, la teología moral se empezó a convertir en más legalista preocupada por el correcto cumplimiento de los mandamientos que encierran el querer divino. Es aquí donde la moral y el derecho positivo dan comienzo a su maridaje. ${ }^{6}$

4 Cf. M. DOLDI, Fondamenti cristologici della morale in alcuni autori italiani. Bilancio e prospettive, Libreria Editrice Vaticana, Città del Vaticano, 2000, 16.

5 Cf. M.VIDAL, Moral Fundamental. (Moral de actitudes-I), PS Editorial, Madrid, 1990, 122-124.

6 Contra esta unión indebida entre la moral y el derecho positivo se han pronunciado muchos teólogos argumentando la inconsistencia filosófica del positivismo divino propuesto por el nominalismo. Entre ellos destacamos a Royo Marín que contra el voluntarismo divino propio de los nominalistas escribe lo siguiente: "Ni siquiera la voluntad de Dios podría alterar el orden esencial de la moralidad que se funda y apoya en la naturaleza misma de las cosas.Y ello porque, como explica santo Tomás, la existencia de las cosas se debe a la voluntad divina, que quiso libremente crearlas; pero la naturaleza o esencia de las cosas no depende de la voluntad divina, sino remotamente de la esencia misma de Dios y próximamente del entendimiento divino. El arquetipo de todas las cosas está en el entendimiento divino, no en la divina voluntad; y por eso a cada una de las cosas le da Dios el ser que le conviene según su propia e intrínseca naturaleza, tal como la concibe el entendimiento divino, o sea tal como debe ser.Y así, v.gr., Dios no podría legislar que dos y dos sean cinco, o que la blasfemia sea lícita, etc., porque no lo sufre la naturaleza misma de las cosas tal como las ve el entendimiento divino": A. ROYO MARÍN, Teología moral para seglares I. Moral fundamental y especial, BAC, Madrid, 2007, 84. 


\subsection{El reduccionismo sacramental}

La teología del siglo XVI estuvo marcada por algunos factores de considerable influencia. El primero de ellos fue la corriente humanista que invitaba a volver la vista a las fuentes en una triple consideración: la antigüedad grecolatina, la Sagrada Escritura y el estudio de los Padres de la Iglesia.

No vamos a negar que el humanismo influyera en la moral en este período histórico pero los otros dos factores que vertebraron los estudios teológicos de este siglo, como son el nacimiento del protestantismo y la contrarreforma de la Iglesia Católica, lo eclipsaron.

La nueva corriente protestante, entre sus muchos errores teológicos, postulaba la no necesidad de la confesión sacramental para la obtención del perdón de los pecados ya que éstos quedaban sin ser imputados por la fe en Jesucristo como único salvador del género humano. La Iglesia Católica, a través del concilio de Trento, trató de contrarrestar la recua de herejías surgidas de las plumas de los reformadores y ya de paso darle una solución a uno de los problemas pastorales más acuciantes del momento que era la escasa formación de los sacerdotes con cura de almas.

Hasta este período la formación sistemática en teología estaba centralizada en las universidades, pero no todos los candidatos al sacerdocio se formaban en ellas. Hacía falta, pues, ofrecerle, no sólo a los aspirantes a las órdenes sagradas sino también a los que ya la habían recibido, una instrucción doctrinal férrea que les permitiera proteger al pueblo de Dios de los influjos de la corrientes heréticas y que al mismo tiempo los capacitaran pastoralmente para el ejercicio de su ministerio. En concreto, el canon XVIII de los Decreta super reformatione pedía que los estudiantes al sacerdocio aprendieran todo lo necesario para administrar los sacramentos en general y para escuchar las confesiones en particular. Es decir, se hacía necesario proveer a los agentes pastorales con cura de almas el aprendizaje necesario para que los sacramentos por ellos administrados fueran lícitos y válidos.

En este sentido, el concilio tridentino revalorizó la importancia de la teología moral ya que se le solicitaba a esta ciencia los fundamentos para hacer una buena confesión. De este modo se le exigía a la moral una proyección pastoral que permitiera a los confesores el saber precisar los pecados, su número, su especie y las circunstancias específicas en las que éstos se producían. ${ }^{7}$

Cf. M. DOLDI, Fondamenti cristologici ...o.c., 17. En relación a esto último que hemos comentado tenemos que de los cánones que el concilio de Trento le dedica al sacramento de la penitencia el número 7 dice lo siguiente:"Si alguno dijere que para la remisión de los pecados en el sacramento de la penitencia no es necesario de derecho divino confesar todos y cada uno de los pecados mortales de que con debida y diligente premeditación se tenga memoria, aun los ocultos y los que son contra los dos últimos mandamientos del decálogo, y las circunstancias que cambian la especie del pecado; sino que esa confesión sólo es útil para instruir y consolar al penitente y antiguamente sólo se observó para imponer la satisfacción canónica; o dijere que aquellos que 
Una vez establecidos los requerimientos teológicos a la ciencia moral era necesario ahora dotar a los aspirantes al sacerdocio de un espacio académico en el que poder instruirse de un modo adecuado a las exigencias de la época. Es por ello por lo que en el año 1563 el concilio de Trento decretó la creación de los seminarios destinados a la instrucción del clero. El estudio de la teología moral por parte de los nuevos seminaristas estaba estructurado en dos etapas. Una primera que versaba sobre cuestiones prácticas que ayudaran a poder oír las confesiones y una segunda focalizada sobre todo a examinar los casos de conciencia. $^{8}$

Pero una vez estructurados los planes de estudio la siguiente preocupación giró en torno a los manuales de moral que se debían usar. Los manuales clásicos no se ajustaban a las nuevas exigencias de la ética teológica por lo que se vio la necesidad de confeccionar nuevos materiales pedagógicos que se circunscribieran a los objetivos demandados. La compañía de Jesús, que había surgido precisamente en este siglo, se esforzó en buscar una solución didáctica. De hecho, durante toda la segunda mitad del siglo XVI fueron teólogos jesuitas de la talla de Martín Azpilicueta, Juan Polanco, Francisco Toledo o Enrique Enríquez entre otros, los que se dedicaron a escribir diversas obras para adecuar el estudio de la moral a la praxis pastoral. Sin embargo, ninguna de ellas superaba la publicada en el año 1600 por el también jesuita Juan de Azor con el título de Institutionum moralium (Liber) in quibus universae quaestiones ad conscientiam recte aut prave factorum pertinentes breviter tranctantur.

Este nuevo manual parte del esquema tomista pero lo depura de los tratados especulativos que no son válidos para la vida práctica y lo adecua a los nuevos planes de estudio introduciendo el tratado sobre la conciencia, fundamental para poder abordar los casos en la confesión. Asimismo el contenido lo hace pivotear sobre el decálogo, dándole con ello a la ética teológica un carácter más jurídico. ${ }^{9}$

\subsection{El encasillamiento jurídico}

Como se puede apreciar, la teología moral desde el siglo XVI en adelante quedó clausurada en el ámbito meramente sacramental. Lo importante era garantizar la licitud y la validez de los sacramentos. Por eso no debe extrañarnos que fuera precisamente a partir de este momento donde se empezara a entrelazar la

se esfuerzan en confesar todos sus pecados, nada quieren dejar a la divina misericordia para ser perdonado; o, en fin, que no es lícito confesar los pecados veniales, sea anatema": DZ 917 (cf. CONCILIO DE TRENTO; Sesión XIV c.7 en H. DENZINGER, El Magisterio de la Iglesia. Enchiridion symbolorum definitionum et declarationum re rebus fidei et morum, Herder, Barcelona, 1963, 262).

8 Cf. L. VEREECKE, "Historia de la Teología Moral" en F. COMPAGNONI; G. PIANA; S. PRIVITERA (dirs), Nuevo Diccionario de Teología Moral, San Pablo, Madrid, 1992², 832.

9 Ibidem, 833. 
moral con el derecho canónico. De hecho, éste poseía una variedad de leyes canónicas que obligaban en conciencia por lo que era necesario seguirlas a la hora de hacer la confesión. Además, a esto hay que sumarle el hecho de que en la enseñanza que se impartía en muchos centros académicos -fueran regentados por los jesuitas o no- no estaba presente el derecho canónico como materia curricular por lo que la teología moral tenía como función paliar esta carencia. De este modo el moralista se convertía también en jurista.

A ello contribuyó de un modo conspicuo la presentación del propio contenido de la ética teológica siguiendo el esquema del decálogo presentando cada uno de los temas de la moral en función de cada uno de los mandamientos. Este esquema tiene una ventaja clara que es la facilidad con la que se puede presentar todos los temas de la moral pero tiene dos dificultades que merecen ser tenidas en cuenta.

La primera de ellas es que posee un alto riesgo de estancarse en los postulados éticos del Antiguo Testamento sin tener presente todo el mensaje moral predicado y enseñado por Jesús de Nazaret. Lamentablemente fue a partir de este período donde nuestra disciplina se separa de la dogmática e inicia su vaciamiento, casi por completo, de la cristología.

Y la segunda dificultad es que este método de la presentación del contenido puede enfatizar la dimensión normativa y legal que conlleva el vocablo "mandamiento", originándose con ello el nacimiento de una moral marcadamente legalista y normativa. ${ }^{10}$ La preocupación básica no era el crecimiento espiritual sino en saber qué era lo que se podía o no se podía hacer. Precisamente por esto el ideal de la perfección cristiana ya no formaba parte de la moral en general sino de la ascética en particular quedando reducida a la vida religiosa. En cambio, la inmensa mayoría de los fieles, que son los laicos, debían sólo preocuparse por el mínimo exigido para poder estar en regla con la norma cayendo así en un minimalismo ético.

Efectivamente, el interés estaba puesto en no cometer una infracción a la norma. Pero a veces existían dudas acerca de la inobservancia de la ley, es decir, no quedaba claro si una determinada acción o bien su omisión constituían un pecado. Fue por esto por lo que los moralistas, a partir de este momento histórico ${ }^{11}$ fueron elaborando lo que se denominó sistemas de moral o sistemas de

10 Si bien es cierto que el esquema del decálogo ha sido, y en parte sigo siendo, un método de presentación del contenido de la moral no menos cierto es que dicho método siguió conviviendo con el empleado por santo Tomás de Aquino en la Summa Theologica que consistía en presentar ese mismo contenido según el esquema de las virtudes teologales y las cardinales. No obstante, el que se impuso en las Instituciones Morales fue el primero de ellos. Cf. A. FERNÁNDEZ, Moral especial, RIALP, Madrid, 2005³, 14-17.

11 El siglo XVI estuvo también marcado por los nuevos descubrimientos geográficos y todo lo que ello implicó. Las relaciones comerciales que Europa mantuvo con América hicieron que los moralistas introdujeran otros temas de interés como la ética de las relaciones internacionales, la ética del comercio, de la usura, del préstamo, del precio justo de los productos comercializados, etc. 
moralidad $^{12}$ cuya finalidad era ayudar a los creyentes, pero en particular a los confesores, a convertir una duda, ya sea especulativa o ya sea práctica, en una certeza moral que dé garantías de la moralidad de la acción sobre la que recae la hesitación. ${ }^{13}$

Con esto se acentúa aún más si cabe, el encasillamiento jurídico de la moral, que se convierte en eminentemente pragmática dirigiendo su mirada al suelo de la praxis del acto humano, separándose, como ya lo hemos apuntado, de la dogmática y de la ascética. Ya no se trata de una ciencia que ayude al hombre en el crecimiento de la virtud sino que se trata de una disciplina que enseña que es lo mínimo que hay que hacer para no pecar.

\section{INICIO DEL CAMINO HACIA LA RENOVACIÓN CRISTOLÓGICA DE LA MORAL}

Como ya hemos indicado al inicio de nuestro trabajo, el siglo $X X$ ha sido un período importante en cuanto a la renovación cristológica de la moral. Pero dicha renovación no surgió de la noche a la mañana sino que ha tenido un largo proceso de preparación en el ámbito de nuestra disciplina. Un recorrido que arranca en el siglo XVIII de manos de san Alfonso María de Ligorio y que continuó en el siglo XIX en el ámbito de la teología alemana e italiana. A ello dedicaremos los siguientes apartados.

12 “La expresión 'sistema de moral' fue acuñada por Alfonso de Ligorio y de él pasó al uso común de la moral católica. Sistema de moral no significa método moral, concepción de la moral o fundamentación/justificación de la Teología Moral. Indica la forma de realizar un juicio vinculante de la conciencia moral ante leyes inciertas objetivamente. El sistema consiste en la propuesta de determinados principios reflejos para hacer ese juicio de conciencia y salir así de la duda": M. VIDAL, Historia de la Teología Moral. De Trento al Vaticano II. I Crisis de la razón y rigorismo moral en el Barroco (s. XVII), PS, Madrid 2014, 710.

13 A continuación vamos a presentar los distintos sistemas morales que se fueron gestando en este período y que ayudaron a los moralistas a elegir cuando se daba una duda. Los iremos presentando de un modo decreciente, es decir, de mayor a menor rigorismo según la clasificación hecha por el teólogo español Royo Marín:

"10 TUCIORISMO ABSOLUTO: Es obligatorio seguir siempre la sentencia más segura, que es la que favorece a la ley, a no ser que la sentencia que favorece a la libertad sea completamente cierta. $2^{\circ}$ TUCIORISMO MITIGADO: Hay que seguir siempre la sentencia favorable a la ley, a no ser que la que favorece a la libertad sea probabilísima.

$3^{\circ}$ PROBABILIORISMO: Hay que seguir siempre la sentencia favorable a la ley, a no ser que la que favorece a la libertad sea más probable que la otra.

$4^{\circ}$ EQUIPROBABILISMO: Para seguir la opinión favorable a la libertad es preciso, al menos, que sea igualmente probable que la que favorece a la ley.

$5^{\circ}$ COMPENSACIONISMO: Es lícito seguir la opinión menos probable (con tal que sea verdaderamente probable) si hay causa suficientemente proporcionada para exponerse al peligro de quebrantar la ley según las reglas del voluntario indirecto. De lo contrario, es obligatorio seguir la opinión más probable.

$6^{\circ}$ PROBABILISMO: Puede seguirse la opinión menos probable, con tal que sea verdaderamente probable.

$7^{\circ}$ LAXISMO: Puede seguirse cualquier opinión probable, aunque sea tenuemente probable": A. ROYO MARÍN, Teología moral...o.c., 181-182. 


\subsection{La moral alfonsiana}

San Alfonso María de Ligorio, para su formación religiosa y sacerdotal recibió la enseñanza de la moral tal y como la hemos descrito en los apartados anteriores. Su interés era examinar los casos de conciencia para poder administrar el sacramento de la penitencia según la doctrina rigorista y jurídica de la época. De hecho él basó su formación moral estudiando Theologie Morale, obra escrita por Francisco Genet quien destacó por ser un enemigo acérrimo de la moral laxa. En su libro, Genet aconsejaba a los que se preparaban para recibir el sacerdocio y a aquellos que ya lo habían recibido a que en el sacramento de la confesión ejercieran la severidad en el examen de conciencia y a que negaran la absolución sacramental si intuían que éste no se había hecho correctamente. ${ }^{14}$

Es sabido que en la primera etapa de su formación, San Alfonso María de Ligorio estuvo bajo la influencia de todos aquellos maestros que en el ámbito de la moral se adherían al sistema del probabiliorismo y es este sistema el que utilizó en gran medida nuestro autor, al menos en los primeros años de su ministerio ya que su preocupación era no fallar como confesor y poder llegar así a una sentencia rígida. De este modo hizo suyo el rigorismo ${ }^{15}$ como el único modo de entender la moral.

Pero el contacto directo con la gente que le proporcionaba las misiones populares hizo que fuera tomando conciencia del tremendo daño que una mentalidad rigorista ejercía en las personas. Esta idea se vio acentuada a partir del año 1730 cuando por prescripción médica tuvo que retirarse a las montañas para poder recuperar su salud. En el tiempo que duró su recuperación tuvo la oportunidad de entrar en contacto con los campesinos y con los pastores de la zona. Se sorprendió al comprobar, por un lado, que carecían de una formación sólida en los principios de la fe y, por otro, que habían abandonado casi por completo las prácticas religiosas. Este hecho lo llevó a gestar en su mente la idea de crear una congregación de misioneros que tuviera como cometido atender espiritualmente a la gente del campo. ${ }^{16}$

Durante su estancia en las montañas se preocupó por buscar a los pecadores y pronto entendió que mantener una actitud rígida y dura con ellos, que en

14 Esta obra fue escrita originariamente en lengua francesa pero pronto fue traducida y publicada en 1702 al latín con el título de Theologia moralis seu resolutio casuum conscientiae juxta Sacrae Scripturae, Canonum et Sanctorum Patrum mentem, alcanzando una gran difusión tanto en Alemania como en Italia.

15 "El rigorismo es el fruto de la reacción contra el laxismo. Las condenas del magisterio, aunque no toman posición sobre el principio del probabilismo, contribuyen a la aparición del rigorismo. En 1665-1666, el papa Alejandro VI condenó 45 proposiciones laxistas (DS 2021-2065); en 1679 el papa Inocencia XI condenó otras 65 (DS 2101-2167); la Sorbona de París y la universidad de Lovaina censuraron numerosas proposiciones de casuistas. En 1657 la Orden de predicadores se separó del probabilismo para tomar como doctrina oficial el probabiliorismo: hay que seguir siempre la opinión más probable": L. VEREECKE, "Historia de la Teología Moral” en F. COMPAGNONI; G. PIANA; S. PRIVITERA (dirs), , ....c., 836.

16 Cf. L.C.L. MARQUES, "Alfonso María de Ligorio" en C. LEONARDI; A. RICCARDI; G. ZARRI (Dirs), Diccionario de los santos I, San Pablo, Madrid, 2000, 129-135. 
su inmensa mayoría eran personas sencillas, humildes y de escasa o casi nula instrucción, lejos de ayudarlos a vivir la conversión los encerraba en la desesperación de no alcanzar nunca la vida eterna.

Por eso, a partir de su experiencia personal como confesor, predicador y misionero, San Alfonso María de Ligorio fue paulatinamente construyendo su propia Theologia Moralis que tendrían un método y un sistema propio. El método no es otro más que presentar la misericordia de Dios hacia los pecadores teniendo como centro la verdad salvífica. Algo que ya se dejaba apreciar en sus predicaciones, pues dejó de hablar de la condenación del fuego eterno como destino para los pecadores y comenzó a enseñar y explicar las parábolas que en los evangelios Cristo usa para hablar de la misericordia del Padre. Fue precisamente la asunción de este método lo que lo llevó a cambiar de sistema, abandonando el probabiliorismo por caer en el rigorismo y asumiendo el equiprobabilismo.

Con esto nuestro autor pretendía no centrar la atención sólo en los principios teóricos que regulan el comportamiento humano sino poder aterrizar también en la particularidad de las personas. Sería como equiparar la moral a la medicina. El médico, aunque diagnostica una enfermedad a partir de los principios genéricos no trabaja para curar "la enfermedad" sino para curar al "enfermo". Por lo tanto debe individualizar su acción para dirigirla hacia una persona concreta ya que una determinada enfermedad no se presenta ni actúa de igual modo en todos los pacientes. Pues bien, en esta misma línea de actuación debe incluirse el moralista, que partiendo de principios generales debe acudir al pecador en particular para ayudarlo de un modo personalizado. Es la persona en su vivir moral la que debe ser atendida pastoralmente para ayudarla a salir de su situación de pecado y encaminarla hacia su crecimiento espiritual.

Con ello lo que se pretende es salir del minimalismo ético en el que el positivismo jurídico había encerrado a la moral para poder llevar a la persona al camino de la perfección cristiana. Ya no se hablaría sólo del pecado sino sobre todo de la acción de la gracia.

Pero lo que más destaca en la enseñanza de la moral en el pensamiento de San Alfonso María de Ligorio fue el recurso al misterio de Cristo. En Cristo, Dios no sólo se manifiesta sino que les expresa a los hombres su amor. De este modo, el amor misericordioso que Cristo ofrecía a los pecadores con los que se encontraba en su vida pública pasa a ser el motor de su acción pastoral. Todavía más, introduce ese amor misericordioso en el propio sacramento de la penitencia ya que como confesor quería juzgar y orientar las conciencias del mismo modo que Nuestro Señor Jesucristo lo hacía en su encuentro con los pecadores de los que se nos habla en los evangelios. ${ }^{17}$

17 Cf. M. DOLDI, Fondamenti cristologici...o.c., 20-24. Cf. J.L. LLANES; J-I. SARANYANA, Historia de la Teología, BAC, Madrid, 19962, 231-233. 


\subsection{El ámbito alemán}

La renovación de la teología moral en el ámbito alemán se encuentra circunscrita a la acción académica de la Escuela de Tubinga. A este nuevo impulso teológico influyó de un modo notorio las ciencias humanas en general y la filosofía en particular, sobre todo el pensamiento kantiano que estuvo muy presente en el contexto universitario. No menos importante fue el recurso a la Sagrada Escritura que tantos beneficios aportó a los estudios de nuestra disciplina.

Tres autores merecen ser destacados: J.M. Sailer (1751-1832); J.B. Hirscher (1788-1865) y F.X. Linsemann (1835-1898).

El primero de ellos se puede considerar el más importante de los tres. Su obra más representativa en el campo de la teología moral es Handbuch der christlichen Moral. En ella presenta una visión orgánica y sistemática de la ética cristiana dirigida tanto a los sacerdotes como a los laicos. Para él, la moral no debe reducirse a la observancia estática de los mandamientos sino que debe poner en el centro la caridad y la vida de la gracia. En este sentido, la libertad del hombre juega un papel importante como respuesta a la iniciativa de Dios.

Se aprecia, por tanto, en él un intento de volver a ligar la moral a la dogmática y a la ascética. Sin embargo, su pensamiento sigue de alguna manera aferrado a la casuística.

El segundo de los autores destacables de la Escuela de Tubinga es, como hemos indicado, J.B. Hirscher. Se preocupó por dotar a la Teología Moral de un fundamento bíblico que era algo de lo que carecía esta disciplina desde hacía siglos. Su obra más significativa en el ámbito que nos ocupa fue Christliche Moral als Lehre von der Verwirklichung des göttlichen Reiches in der Menschheit. No se trata de un manual al estilo clásico ya que no era partidario del método escolástico. Lo que hace es colocar la noción de Reino de Dios como eje vertebrador de su pensamiento. ${ }^{18}$

Para nuestro autor, el hombre ha sido creado por Dios como ciudadano de ese Reino, pero como consecuencia del pecado ha sido expulsado de él. Sin embargo, a pesar de su situación de naturaleza caída sigue poseyendo la inteligencia, la voluntad y la conciencia, tres elementos fundamentales que le permiten vivir según los principios éticos. Junto a la vivencia de estos principios, Hirscher expone la idea de que el hombre puede volver a recuperar el Reino perdido por una disposición de la gracia manifestada históricamente en la persona de

18 "Con el tema del reino de Dios, Hirscher entroncaba la moral no sólo con la Escritura, sino con el centro de la predicación de Cristo. No cabe duda de que con ello recurre a un principio fundamental. Se le acusó en su tiempo de algunas inexactitudes dogmáticas que luego corrigió y de su falta de conocimiento de los grandes autores de la escolástica, ya que su método, a juicio de Häring, fue demasiado crítico con la neoescolástica": J.A.SAYÉS, Teología Moral Fundamental, EDICEP, Valencia, 2003, 78. 
Jesús de Nazaret. Es Cristo el que inspira la inteligencia del hombre para que se percate de su error, mueve a la voluntad en la búsqueda del bien y despierta a la conciencia adormecida por el pecado. En definitiva, para Hirscher la moral católica no debe seguir siendo enseñada basada en la ley sino a partir de la experiencia del Reino de Dios que ha sido revelado y manifestado en la persona histórica de Jesús de Nazaret.

El tercer autor de la Escuela de Tubinga que merece ser resaltado fue F.X. Linsemann. Se inserta en la línea de los otros dos. Su obra más característica es su Lehrbuch der Moraltheologie, una auténtico manual en el que centra su preocupación en insertar a la moral dentro del estatuto epistemológico de la Teología. Para nuestro autor la moral no sería una ciencia en sí misma sino que lo es en tanto en cuanto se encuentre ligada a la dogmática. Del mismo modo que la ética filosófica debe presuponer la metafísica, la moral debe presuponer la dogmática. Si ésta debe encargarse de estudiar a Dios en sí mismo como suma verdad, aquélla debe ocuparse de cómo cumplir su voluntad. Pero deben permanecer unidas.

Por otro lado, Linsemann enfoca también su atención en el positivismo jurídico en el que había caído la moral tridentina. Él no niega la importancia de la ley pero sostiene que sólo una pequeña porción de nuestros deberes y obligaciones morales se encuentran escritas en ella. El resto va a depender del ejercicio de nuestra libertad, una libertad que se materializa en decisiones concretas.

En definitiva, la Escuela de Tubinga desempeñó un papel importante en la renovación de la moral católica. Propició el uso de la Sagrada Escritura para fundamentarla, la vinculó a la dogmática para darle carácter teológico y la dotó de un contenido cristológico. ${ }^{19}$

\section{3. Ámbito italiano}

En Italia la Teología Moral experimentó un menor desarrollo en comparación con Alemania. Pero creemos que el esfuerzo que llevó a cabo Antonio Rosmini (1797-1855) por restaurar nuestra disciplina no debe ser obviado. Su obra Trattato della coscienza morale publicada en 1840 fue un vivo intento de reformar la moral introduciendo en ella tanto la reflexión teológica como la filosófica. Consideraba que la ética natural no era suficiente para afrontar los retos de la vida moral sino que se hacía también necesario acudir a la revelación para entender las exigencias que Dios le pide al creyente.

Pero la unión de filosofía y teología no fue la única innovación de Rosmini. A nuestro modo de ver su impronta cristológica fue lo más novedoso por cuanto que proponía la imitación de Cristo como medio de perfeccionamiento moral.

19 Cf. J.R. FLECHA ANDRÉS, Teología moral fundamental, BAC, Madrid, 1994, 57-58. 
Sin duda esto fue una enorme novedad en la época ya que la ética y la ascética estaban totalmente separadas.

\section{LA RENOVACIÓN DE LA TEOLOGÍA MORAL EN EL SIGLO XX}

Como ya hemos indicado, los intentos de una renovación en la teología moral arrancaron en el siglo XVIII gracias a los denodados esfuerzos llevados a cabo por el fundador de los Redentoristas y continuados en el siguiente siglo por la Escuela de Tubinga con alguna que otra participación aislada en Italia.

Todo esto sirvió para prepararles el camino a los moralistas del siglo XX que llevaron de una manera más sistematizada la reforma de nuestra disciplina. La restauración de la misma en esa centuria ha atravesado cuatro etapas en las que se han realizado trabajos y propuestas significativas orientadas a ese fin: una primera que va desde 1900 a 1930 donde se inicia una renovación tomista de la moral; una segunda de 1930 a 1960, en la que se destaca la impronta bíblica y litúrgica de esa reforma; una tercera de apenas una década, de 1960 a 1970, etapa que coincide con la celebración del Concilio Vaticano II y una cuarta y última etapa que sería el período postconciliar.

\subsection{El período de $1900-1930$}

Entre los moralistas existía la convicción de que el minimalismo ético surgido del positivismo jurídico no garantizaba el crecimiento espiritual del creyente. La connivencia entre moral y derecho había provocado que se pusiera más atención en la norma que en la virtud. Esto había hecho que se hablara más de pecado que de la gracia. Precisamente esto fue lo que se intentó corregir en esta etapa. Para ello se empezó a presentar la moral no siguiendo el esquema del decálogo sino el de las virtudes que fue el utilizado por Santo Tomás de Aquino. Con ello se pretendía una presentación más personal de los principios éticos algo que se vio favorecido por el desarrollo de la Teología Espiritual como disciplina.

No obstante, este intento no llegó a alcanzar la fuerza suficiente como para que se produjera el abandono de la casuística. Ésta estaba y está fuertemente vinculada a la normatividad imperante en nuestra ciencia desde hace centurias y que emana de una concepción marcadamente jurídica de la ética. El factor que condicionó este hecho fue la publicación, en 1917, del Código de Derecho Canónico, algo que retrasó la liberación de la moral de su encuadre legal. De hecho el manual más importante de este período fue Die Katholische Moral und ihre Gegner escrito por Joseph Mausbach, que si bien incorpora la perspectiva antropológica de la perfección del ser y, por tanto, del crecimiento espiritual en la gracia, no deja de ser significativo el hecho de que siga presentando el contenido de la moral siguiendo el esquema del decálogo. 


\subsection{El período $1930-1960$}

Esta etapa va a estar caracterizada por la relación de otras disciplinas teológicas con la moral. Al menos tres influencias son dignas de mención: la litúrgica, la bíblica y la pastoral. En cuanto a la primera tenemos que todo el movimiento litúrgico pretendía que la liturgia no estuviera desencarnada de la vida real del creyente sino que tuviera su incidencia en el actuar cristiano. Con respecto a la segunda, el movimiento bíblico no quería presentar los estudios de la Sagrada Escritura como un fin en sí mismo sino que éstos tuvieran como finalidad iluminar la vida moral del cristiano para que éste pudiera llegar a tener una existencia más plena a la luz de la Revelación.Y en relación a la tercera influencia anteriormente reseñada tenemos que la pastoral, unida al movimiento ecuménico propio de la época, tenía entre sus propósitos apostar por recuperar el anuncio kerigmático con lo que las cuestiones abstractas propias de la dogmática debían ceder el paso a las cuestiones más prácticas propias de la vida moral de los fieles.

A tenor de todo esto no nos debe extrañar que surgiera la necesidad de publicar otros manuales de moral que recogieran estas consideraciones. Manuales que superaran la moral del confesionario en beneficio de otra que estuviera más focalizada en el obrar del creyente. Teniendo en cuenta la importancia de la Escuela de Tubinga en el desarrollo de la teología en el siglo XIX, no debe resultar inesperado que fuera en Alemania donde comenzara a publicarse estas obras. Una de las más importantes fue la escrita por Fritz Tillmann en colaboración con T. Steinbuchel yT. Muncker publicada con el título Handbuch der Katholischen Sittenlehre. Tillmann se encargaría de exponer la nueva moral desde una perspectiva bíblica y cristológica utilizando para ello dos de los cuatro tomos de los que consta la obra. En concreto el tercero y el cuarto titulados Die idee der Nachfolge Christi y Die Verwicklichung der Nachfolge Christi respectivamente. Por su parte, Muncker se encargaría de dotar a la obra de los fundamentos psicológicos escribiendo el tomo primero mientras que de los fundamentos filosóficos se ocuparía Steinbuchel en el segundo tomo. ${ }^{20}$

Lo interesante en la obra de Tillmann es que propone la imitación de Cristo como el núcleo del obrar cristiano.Y para hacer esta propuesta se ayuda de dos elementos fundamentales. El primero es de la Sagrada Escritura. Tillmann era exégeta por lo que tenía un gran conocimiento de los estudios bíblicos. La Biblia debía constituir el alma de toda buena teología y la ciencia moral no debía prescindir de ella. El segundo elemento fue el personalismo de Max Scheler para quien la personalidad moral llega a la perfección dirigiéndose más por un modelo que por una norma. ${ }^{21}$ En este sentido, la permeabilidad que la corriente

20 Cf. A.M. JERUMANIS, In Cristo, con Cristo, per Cristo. Manuale di teología morale fondamentale. Approccio storio-sistematico, Edizioni Camilliane, Torino, 2013, 354.

21 Para un mayor conocimiento del pensamiento de Max Scheler y de la influencia del personalismo en las actos humanos cf. M. MORENOVILLA, " Personalismo alemán” en M. MORENO VILLA (Dir), Diccionario de pensamiento contemporáneo, San Pablo, Madrid, 1997, 932-934. 
personalista tuvo en la teología moral hizo que ésta fuera dándole menos entidad al precepto que hay que seguir para dársela a la persona que hay que imitar. De este modo Jesucristo aparece como el modelo por antonomasia de cuyo seguimiento e imitación dependerá ahora todo el orden moral.

Esta idea central y neurálgica en el pensamiento de Tillmann, fue sintetizada por nuestro autor en otra obra titulada Der Meister ruft. Él entendió que la nueva moral no podía estar dirigida sólo a los especialistas sino a los creyentes en general, de ahí que decidiera presentarle al gran público una síntesis de lo que se afirmaba en su monumental obra en cuatro tomos. En dicha síntesis, que alcanzó gran difusión no sólo dentro sino también fuera de Alemania ${ }^{22}$, trató de explicar en qué consistía la imitación de Cristo. Ésta debe ser entendida en clave de sequela ya que a fin de cuentas el evangelio constituye una llamada de Dios a seguirlo. Una invitación que tiene alcances universales ya que todos los hombres de todos los tiempos pueden participar de ella. Para nuestro autor la finalidad de este seguimiento es poder llegar a ser hijos adoptivos de Dios, para que siendo hijos en el Hijo podamos asemejarnos al Padre. ${ }^{23}$ En este proceso, el creyente va paulatinamente experimentando su deseo de buscar con sinceridad la voluntad de Dios a la par que comienza a sentir una aversión al pecado que lo aleja de su modelo.

Asimismo insiste en el hecho de que no es el hombre el que por sus solas fuerzas naturales el que inicia la sequela, sino que es el mismo Dios el que incoa el proceso. Se trata de una iniciativa gratuita y libre de Dios que por medio de la gracia lanza la invitación a todos los hombres. De este modo, se pierde esa noción de moral que lo hace depender todo del mérito o demérito del individuo para pasar a otra en la que criatura y creador se unen para recorrer juntos el camino de las exigencias éticas.

En conclusión, la moral de Tillmann es una moral dinámica, cristocéntrica y abierta a la gracia que pone delante de cada hombre un modelo a imitar y las ayudas divinas necesarias para realizarlo. Siendo esto así, se aprecia en su pensamiento una visión positiva de la moral basada en la persona de Jesucristo y no tanto en el pecado.

Pero si importantes fueron las aportaciones de Tillmann en este período no menos notables fueron las realizadas por Bernard Häring, considerado por muchos como el más egregio de los moralistas católicos de todo el siglo XX. Su renovación de la ética cristiana está basada en la fundamentación en la Sagrada Escritura y en su prisma cristológico. Muchas y variadas son sus publicaciones pero su obra más característica fue su tratado de Teología Moral publicado en el

22 Esta obra pronto fue traducida al italiano con el título Il Maestro chiama alcanzando una gran difusión en el país transalpino marcando las líneas fundamentales en el estudio de la moral previa al concilio. En cuanto al esquema prácticamente sigue el mismo que marcó en el siglo XIX la Escuela de Tubinga: la relación del hombre consigo mismo; la relación del hombre con su prójimo y con la sociedad civil de la que forma parte.

23 "Quale è lo scopo della séquela di Cristo? Non altro che quello di diventare figli adottivi di Dio, di salire verso la perfezione rendendosi grado grado sempre più simili al Padre che è nei cieli": F. TILLMANN, Il maestro chiama, Brescia, 1945, 13. 
año 1954 con el título de Das Gesetz Christi. Moraltheologie dargestellt für Priester und Laien. Se trata de una obra que experimentó una enorme difusión llegándose a imprimir en sus primeros años más de 200.000 copias traducidas a 14 lenguas. Pronto se empezó a utilizar en los seminarios y se convirtió en el manual preferido de los docentes para la formación de sus pupilos en esta materia.

Häring se alinea con Tillmann al presentar la moral desde la perspectiva cristocéntrica. Hace suya la idea de la sequela y la de la imitación de Cristo como basamento de toda reflexión teológico moral. Él mismo lo dice en la introducción de su obra. Escuchémoslo:

El centro, norma y finalidad de la Teología moral cristiana es Cristo. Cristo en persona es la verdadera y auténtica ley del cristiano, puesto que es Cristo su único Señor y salvador. Por Él y en Él tenemos la vida: por Él y en Él tenemos la ley de esta vida. Para comprender todas las exigencias de la vida cristiana, no basta considerar los términos del decálogo; ni siquiera es suficiente mirar sólo lo que la voluntad de Dios impone y exige; lo primero que se ha de pesar es el amor que Dios nos profesa, lo que nos exigen sus amorosos dones. Ahora bien, Dios nos lo dio todo en Cristo; en Él nos reveló las últimas profundidades de su amor. En ese amor de Cristo y por ese amor nos pide un amor recíproco, esto es, nos pide una vida "cristiana" de veras, cristiforme. La vida cristiana se nos presenta así como una imitación, como un "seguimiento" de Cristo; mas no una imitación o seguimiento puramente exterior, ni una copia externa, aunque fuera por amor y obediencia; no, la vida cristiana es, ante todo, una vida en Cristo Jesús. ${ }^{24}$

Como se puede apreciar, Häring presenta el evento Cristo como punto de partida y punto de llegada de toda la moral. Es Dios el que llama al hombre en la persona de Jesucristo para que seamos iguales a Él, es decir, para que imitándole podamos cristificarnos. En este sentido, la antropología se entiende a la luz de la cristología. La norma moral ya no es un precepto sino una persona y la valoración moral de nuestras acciones estarán en función del tipo de respuesta que demos al seguimiento de esa persona. De este modo el pecado viene comprendido como una respuesta negativa a la llamada de Dios. Sería la negación voluntaria a la realización del proyecto personal al que hemos sido llamados y por el que hemos sido creados.

Todas estas ideas pudieron ser expuestas por nuestro autor no sólo a través de sus publicaciones en libros y artículos sino que también desde su cátedra de profesor en la Academia Alfonsiana creada en 1949 en Roma con el objetivo de instruir en materia de moral a los sacerdotes venidos de muchos países del mundo. Este centro académico, especializado en la enseñanza de la ética teológica, ofrecía a sus alumnos una formación de la moral católica con una fuerte fundamentación bíblica y patrística con un marcado carácter cristocéntrico.

24 B. HÄRING, La Ley de Cristo. La teología moral expuesta a sacerdotes y seglares, Herder, Barcelona, $1964^{4}, 29$. 


\subsection{Período de 1960 a 1970}

En este tercer período de estudio de la teología moral en el siglo XX, lo más significativo fue la celebración del Concilio Vaticano II inaugurado por el Papa Juan XXIII en 1962 y clausurado por PabloVI en 1965. Tratándose, por tanto, del evento más notorio, no sólo de este período sino de todo el pasado siglo, vamos a centrar nuestra atención en las líneas de renovación que se trazaron en él con respecto a nuestra disciplina.

Ya ha sido dicho que entre los textos conciliares no hay ninguno cuya temática sea en exclusividad la moral. Ésta aparece diseminada de un modo transversal entre los distintos documentos conciliares. Sin embrago, la idea primigenia fue la de incluir un escrito que versara exclusivamente sobre la ética cristiana.

Y así fue como en el año 1961, una comisión preparatoria recibió el encargo de confeccionar un esquema que recogiera los puntos fundamentales de la moral católica para que fuesen estudiados y trabajados durante las sesiones del concilio.

Los responsables de la elaboración de dicho esquema fueron Huerth S.J., Guillon O.P., y Lio O.F.M, tres profesores de Teología de la línea de Pío XII y consultores del Santo Oficio. Ellos prepararon un borrador cuyo título fue De Ordine Morali que recogía de un modo sintético y sistemático todos los contenidos de la moral católica. No está de más decir que la formación de estos tres teólogos era de corte tradicionalista, centrada en la casuística y teniendo el derecho canónico como basamento de sus postulados.

El texto en cuestión estaba estructurado en seis capítulos cada uno de los cuales constaba de dos partes, una expositiva, cuya finalidad era afianzar la enseñanza de la moral tradicional, y otra que se dedicaba a condenar los distintos errores teológicos sobre cuestiones de ética cristiana.$^{25}$ Los seis capítulos iniciales de este esquema fueron los siguientes:

1.- DE FUNDAMENTO ORDINIS MORALIS: 1.1.- De indole objectiva ordinis moralis; 1.2.- Ordo moralis absolutus; 1.3.- Deus custos, iudex, vindex ordinis moralis; 1.4.- Ordinis moralis duplex manifestatio; 1.5.- Contentum ordinis moralis; 1.6.- Damnantur errores.

2.- DE CONSCIENTIA CHRISTIANA: 2.1.- Quid conscientia; 2.2.- Conscientia recte efformanda; 2.3.- De conscientia erronea; 2.4.- Pseudoconscientia autonoma; 2.5.- Conscientia segnata Christi veritate ac caritate.

3.- DE SUBIECTIVISMO ET RELATIVISMO ETHICO: 3.1.- Lex evangelica et conditiones individuales; 3.2.- Necessaria cognitio individualium; 3.3.- Adagia falsa; 3.4.- Falsum adagium de amore criterio moralitatis.

25 El carácter condenatorio de este documento ha llevado a algunos autores a catalogarlo como una especie de Syllabus moral, recordando aquel documento publicado por la Santa Sede en 1864 en la que se condenaban las ideas modernistas. Cf. PH. DELHAYE, "L'apporto del Vaticano II alla teologia morale" en Concilium 8 (1972), 909. 
4.- DENATURALIET SUPERNATURALIDIGNITATEPERSONAEHUMANAE: 4.1.- Homo factus ad immaginem Dei; 4.2.- Arbitrii libertas vindicatur; 4.3.- Defensio dignitatis humanae contra artificia falsa; 4.4.- Scientia, artes liberales, technica; 4.5.- Progressus technicus et Regnum Dei; 4.6.- Progressus technicus et progressus religioso-moralis.

5.- DE PECCATO: 5.1.- Quo sensu regno peccati sit destructum; 5.2.- Peccatum mortale cum et ex contemptu; 5.3.- Peccata ex debilitate; 5.4.- Falsae theoriae psycologicae; 5.5.- De profectu christifidelis in via iustitiae; 5.6.- Magnum poenitentiae officium; 5.6.- Errores damnantur.

6.- DECASTITATEETDEPUDICITIA CHRISTIANA: 6-1.- Origo et natura sexus; 6.2.- Homo non dominus absolutus corporis; 6.3.- De castitate in solutis; 6.4.- Defensio et cura castitatis; 6.5.- Quidam errores censurantur. ${ }^{26}$

Este esquema inicial compuesto por seis capítulos le fue entregado al cardenal Alfredo Ottaviani que a su vez lo presentó a la comisión preparatoria del concilio el 15 de enero de 1962. Dicha comisión después de simplificar un poco el esquema lo incluyó en el material que debía ser discutido en el concilio.

Unos meses después, concretamente en julio de ese mismo año, el papa Juan XXIII concedió su autorización para que los documentos examinados por la comisión preparatoria fueran enviados a los padres conciliares para su ulterior análisis y estudio. Dentro de esa pila de documentos se encontraba el De Ordine Morali.

Antes de que concluyese la primera sesión del concilio los participantes en el mismo recibieron, a parte del material inicial entregado por la comisión preparatoria, otra nueva recua de documentos por lo que los textos a estudiar sufrieron un aumento considerable. Toda aquella balumba documentaria con que se empapeló a los padres conciliares debía, por necesidad metodológica, que ser reducida y simplificada. Para este fin se decidió que en el intervalo que va desde la conclusión de la primera sesión hasta la apertura de la segunda, varias comisiones se encargarían de depurar el material para simplificarlo.

La comisión que se ocupó de examinar el De Ordine Morali, entre otros más documentos, estaba encabezada por el cardenal Suenens. Éste tras el análisis del mismo pidió su reelaboración ya que para él la noción de dignidad de la persona debía ser la idea sobre la que pivotase toda la moral católica y esto no se percibía del todo bien en el esquema primigenio. De ahí que él propusiera la fusión con otro esquema presentado en la comisión el De Ecclesia relate ad personam humanam.

El cardenal Suenens no fue el único en discrepar del primer esquema. Ya Ottaviani en una primera inspección había hecho notar algunas consideraciones importantes con respecto al documento. Lo primero que le llamó la atención fue el carácter apologético y polémico del texto pues no solamente presentaba el contenido de la ética cristiana sino que hacía hincapié en los

26 Cf. C. ZUCCARO, Cristologia e morale. Storia, interpretazione, prospettive, EDB, Bologna, 2003, 52. 
errores que en materia moral se predicaban en una cultura plural como lo era ya el contexto geográfico occidental. ${ }^{27}$

Asimismo, llamaba la atención la presencia del capítulo sexto del esquema dedicado a la sexualidad. Esto fue altamente criticado por varios miembros que componían la comisión preparatoria ya que daba a entender que el único pecado al que la Iglesia le dedicaba más importancia era al sexual.

La comisión que presidía Ottaviani estaba compuesta por 35 cardenales, 2 patriarcas, 14 arzobispos, 2 obispos y 4 superiores generales sumando un total de 57 miembros. Aunque todos trabajaron con denuedo en las mejoras del documento quienes más polemizaron con él fueron los cardenales Liénart, Alfrink y Döpfner.

El primero de ellos muestra su descontento ante el tono altamente negativo con que el documento trata la moral, algo que considera totalmente inadecuado para el hombre contemporáneo a quien el concilio se quería dirigir.

También cuestiona el carácter marcadamente individualista de la acción moral de la persona. El documento, en opinión de Liénart, se centra en la valoración moral del acto concreto que el creyente realiza sin tener en cuenta la dimensión social del hombre. Esto se veía como un empobrecimiento sobre todo si se tiene presente los pasos agigantados que se estaban dando en la segunda mitad del siglo XX hacia la construcción de un mundo más globalizado.

Finalmente, el prelado francés elevó su queja ante la clamorosa ausencia de la caridad como contenido propio de la ética cristiana. La inclusión de la caridad en los planteamientos de la teología moral había sido, junto con la incorporación de la cristología, la gran aportación tanto de San Alfonso María de Ligorio como de la Escuela de Tubinga. Sin embargo, el De Ordine Morali había vuelto a un planteamiento neoescolástico donde se le daba más cobertura al derecho que a esta virtud teologal vital para entender las exigencias éticas de la fe cristiana.

La crítica de Alfrink se sitúa también en la misma línea de la de Liénart. Destaca la índole negativa del texto subrayando lo inapropiado que resulta mantener en el documento el tono condenatorio ante los errores en moral. Sostiene, que más que condenar los fallos morales, lo que conviene hacer es preguntarse el por qué éstos se producen en personas que en principio son honestas. Lo que Alfrink pretende con estas correcciones es defender una ética teológica en la que no se separe el acto moral del sujeto que actúa. Efectivamente, el texto se focalizaba sólo en la acción del sujeto para emitir la valoración moral obviando las circunstancias en las que el sujeto agente la ha llevado a cabo.

27 "...non quidem tractatum de re morali, non tractatum de re disciplinari, non scholasticum tractatum, qui omnes quaestiones debere tangere, sed tantummodo actum fuisse de his quae presertim, attentis erroribus qui vastant hodie ordinem moralem..., sunt aggredienda ut per sanam doctrinam expugnantur errores grassantes": "Relatio Em.mi P.D. Alfredi Card. OTAVIANI Praesidis Commissionis Theologiae" en Acta et documenta Conclio Oecumenico Vaticano II Apparando, Series II, Volumen II, pars II, Roma, 1968, 57. 
Por último, Döpfner coincide con Liénart y Alfrink en el tono negativo y polémico del documento, inadecuado, por tanto, para el hombre actual. Pero aparte de esto hay dos observaciones más que hace acerca del documento que creemos que son necesarias traer a colación. La primera es que destaca del texto su lenguaje netamente filosófico y abstracto que no facilita nada el diálogo con el hombre de hoy. Se basa sobre todo en la noción de ley natural ${ }^{28}$ que sería el garante del comportamiento humano, ley que puede ser descubierta sólo por el uso de la razón. ${ }^{29}$ La segunda es que destaca la ausencia de la Sagrada Escritura como fundamento de los principios éticos que deben regular la vida de todo creyente. Esto fue notado no sólo por él sino por casi todos los miembros de la comisión. De hecho uno de los cometidos del Concilio Vaticano II era darle a la Teología en general el marco bíblico del que había carecido desde hacía siglos. El recurso a la Sagrada Escritura por parte de los manuales de teología moral era secundario utilizándola como método de justificación de sus postulados, lo que se conoce como dicta probanda.

Esta falta del uso de la Escritura en el De Ordine Morali traía consigo el problema que nuestra disciplina llevaba arrastrando durante centurias que era el vacío cristológico provocado por la no presentación de Jesucristo como modelo de seguimiento en la vida moral. El documento se centraba, como ya hemos apuntado, en la norma y no en la persona de Jesús. ${ }^{30}$

Junto a todas estas objeciones presentadas de un modo más particular por Liénert, Alfrink y Döpfner la comisión preparatoria advertía de una cuestión no menos importante y que a la larga serviría para darle un golpe definitivo al documento. Dicha objeción tiene que ver con la especificidad de la moral cristiana. En los años previos al concilio existía una fuerte discusión entre los moralistas sobre esta cuestión dividiéndose en dos bandos opuestos. Un primer bando de teólogos sostenía que la especificidad de la moral hay que buscarla en la

28 La noción de ley natural hunde sus raíces en la Antigüedad Clásica y fue asumida posteriormente por el cristianismo. Quien más la integró en la reflexión teológico-moral fue Santo Tomás de Aquino quien la asumió de la filosofía griega. Cf. Sto. TOMÁS DE AQUINO, Summa Theologiae, I-II, q. 94. Para profundizar acerca de este concepcto cf. COMISIÓN TEOLÓGICA INTERNACIONAL, En busca de una ética universal: Nueva perspectia sobre la ley natural, BAC, Madrid 2009; F. CARPINTERO, La ley natural. Historia de un concepto controvertido, Ediciones Encuentro, Madrid, 2008; A.M. GONZÁLEZ, Claves de ley natural, RIALP, Madrid, 2006; M.A. DURAZO, En busca de una ética universal. Análisis del documento sobre la ley natural de la Comisión Teológica Internacional y comparación con las contribuciones de J. Finnis y M. Rhonheimer, Pontificia Universitas Sanctae Crucis, Roma, 2015; cf. F.J. CONTRERAS (Ed), El sentido de la libertad. Historia y actualidad de la idea de ley natural, Stella Maris, Barcelona 2014.

29 "Il De Ordini Morali, presenta la teologia morale secondo una visione essenzialmente filosofica e razionale. Il pensiero si snoda a partire da una visione di Dio Creatore di tutte le cose, infinitamente buono e santo e perciò norma normans di ogni scelta. L'ordine morale trova in Dio la sua consistenza ed anche la sua sicurezza; egli ne è il custode, il giudice, il garante. L'uomo, in tale visione, scopre una legge, sia essa naturale o evangelica, da rispettare e con la quale confrontarsi per decidere circa la moralità dei suoi singoli atti": M. DOLDI, Fondamenti cristologici...o.c., 46.

30 Cf. C. ZUCCARO, Cristología e morale ...o.c., 53-54. 
espiritualidad y más concretamente en la vivencia de los consejos evangélicos: la pobreza, la castidad y la obediencia. Siendo esto así, solamente los religiosos estaban llamados a una vida moral más perfecta.

El segundo bando estaba constituido por aquellos teólogos que se habían adherido al movimiento bíblico y litúrgico que caracterizó el preconcilio. Ellos, basándose en los textos de la Sagrada Escritura sostenían que todos los creyentes están llamados a la santidad y que el camino para alcanzarla es la imitación de Jesucristo.

Está de más decir que de estas dos concepciones de la santidad el documento De Ordine Morali optó por la primera considerando que la santidad es más propia de los que han iniciado la vida religiosa que de los laicos.

Ante todo este elenco de críticas que recibió el documento por parte de los padres conciliares en las comisiones preparatorias tanto del cardenal Ottaviani como del cardenal Suenens, se tomó la decisión de eliminar definitivamente el texto.Y decimos bien, eliminar, porque el De Ordine Morali nunca fue sustituido por otro. Dichas comisiones no fueron capaces de reelaborarlo básicamente por dos motivos. El primero porque el movimiento de renovación moral previo al concilio no era tan fuerte como lo fue el movimiento de renovación bíblico o litúrgico. ${ }^{31}$ De hecho se contó con pocos moralistas como peritos y de entre esos pocos, muchos seguían teniendo una impronta tradicionalista.Y el segundo motivo fue la premura con la que hubo que actuar. Al ser rechazado el texto en su totalidad apenas se contaba con tiempo material para que se pudiera encargar a otro grupo de teólogos moralistas la confección de un documento alternativo que fuese previamente estudiado y analizado por una nueva comisión antes de ser llevado al aula conciliar. ${ }^{32}$

31 El movimiento bíblico había alcanzado una considerable fuerza durante toda la primera mitad del siglo XX. Ha ello contribuyó notablemente el arduo trabajo de muchos biblistas entre ellos, de M.J. Lagrange que fue el fundador de la Ecole biblique et archéologique français de Jérusalem, de la Revue Biblique y fundador también de la colección Études bibliques. En esta misma línea hay que destacar la creación de la Pontificia Comisión Bíblica en el año 1902 o del Pontificio Instituto Bíblico en 1909. Esto es una clara muestra de la importancia que iba ganando los estudios bíblicos dentro de la Iglesia. También es de destacar la aparición del método históricocrítico aplicado a los textos bíblicos, método indispensable para el conocimiento de los textos de la antigüedad y que se valía de distintas etapas: crítica textual, crítica literaria, la crítica de los géneros, la crítica de la redacción y la crítica histórica. Asimismo la publicación en 1943 de la carta encíclica Divino Afflante Spiritu del papa Pío XII contribuyó a darle más impulso a los estudios bíblicos. El movimiento litúrgico también experimentó un gran auge en la primera mitad del siglo XX con autores como L. Beauduin, O. Casel o R. Guardini que heredaron de los autores del siglo XIX, Solesmes, Maredsous, Beuron y Maria Laach las líneas de trabajo para la renovación de la liturgia. Cf. A.M. JERUMANIS, In Cristo...o.c., 334-335.

32 "La mayoría conciliar, creada en noviembre de 1962, no acepta este texto y naufragará con el conjunto de los esquemas de las comisiones preparatorias. Pero, ¿por qué razones no es reemplazado por otro nuevo? Se pueden indicar varias. La historia del concilio demuestra que los grandes textos adoptados por el Vaticano II se deben a los esfuerzos teológicos que le habían precedido. Este es el caso de la liturgia, de la eclesiología, de la exégesis. Ahora bien, el movimiento en favor de la renovación de la moral ha sido relativamente eliminado (sic). Por otra parte, hay 
La consecuencia de esto es el hecho de que no exista entre los documentos delVaticano II ninguno dedicado a nuestra disciplina. La resolución que se tomó para paliar esta deficiencia fue la de diseminar el contenido moral entre los diversos textos que confeccionarían el resultado final.

Entre los documentos del concilio en los que se vertió el contenido moral de un modo más específico, una vez eliminado el De Ordine Morali, tenemos que destacar la constitución dogmática Lumen Gentium. Para algunos teóricos del concilio este texto puede ser considerado como el más solemne. No es nuestro cometido hacer un análisis de todos los capítulos del documento ya que eso excede la pretensión de este estudio pero sí es pertinente dirigir nuestra atención al capítulo quinto donde encontramos la llamada universal a la santidad. Justamente al inicio del texto se nos dice lo siguiente:

"La Iglesia, cuyo misterio está exponiendo el sagrado Concilio, creemos que es indefectiblemente santa. Pues Cristo, el Hijo de Dios, quien con el Padre y el Espíritu Santo es proclamado "el único santo", amó a la Iglesia como a su esposa, entregándose a Sí mismo por ella para santificarla (cf. Eph 5,25-26), la unió a Sí como su propio cuerpo y la enriqueció con el don del Espíritu Santo para gloria de Dios. Por ello, en la Iglesia, todos, lo mismo quienes pertenecen a la Jerarquía que los apacentados por ella, están llamados a la santidad, según aquello del Apóstol: Porque esta es la voluntad de Dios, vuestra santificación (I Thess 4,3; cf. Eph 1,4). Esta santidad de la Iglesia se manifiesta y sin cesar debe manifestarse en los frutos de gracia que el Espíritu produce en los fieles. Se expresa multiformemente en cada uno de los que, con edificación de los demás, se acercan a la perfección de la caridad en su propio género de vida; de manera singular aparece en la práctica de los comúnmente llamados consejos evangélicos. Esta práctica de los consejos, que, por impulso del Espíritu Santo, muchos cristianos han alcanzado tanto en privado como en una condición o estado aceptado por la Iglesia, proporciona al mundo y debe proporcionarle un espléndido testimonio y ejemplo de esa santidad." 33

Es interesante notar como este capítulo recoge el tema de la santidad. Ésta ya no es exclusiva de unos pocos sino de todos los fieles. En cualquier caso, no fue

pocos moralistas en el concilio. Los obispos especialistas en teología han enseñado exégesis y dogma. La elección de los peritos ha eliminado casi totalmente los escasos moralistas favorables a las nuevas tendencias que habían formado parte de las comisiones preparatorias. Será necesario que pase el tiempo para que nombren a algunos de éstos. Casi inmediatamente después, su tiempo se verá absorbido por la preparación de la constitución Gaudium et Spes. Las consecuencias que se derivan de estos hechos serán paradójicamente felices. La antigua moral casuística llega prácticamente a desaparecer. Se pretenderá conseguir una expresión nueva de los imperativos de la fe en consonancia con la estructura, el dogma, la vida de la Iglesia en una palabra, restableciendo las relaciones que los partidarios de la renovación moral casi no se habían atrevido a soñar": PH. DELHAYE, “La aportación del Vaticano II a la teología moral” en Concilium 75 (1972), 209.

33 CONCILIO VATICANO II, Constitución dogmática sobre la Iglesia Lumen Gentium (21-noviembre-1964), n³9 en AAS 65. Para aquellos que estén interesados en la historia de este concilio cf. G.F. SVIDERCOSCHI, Historia del Conclio Vaticano II, Coculsa, Madrid, 1968; G. ALBERIGO, Breve historia del Concilio Vaticano II (1959-1965), Sígueme, Salamanca 2005. 
fácil llegar a esta conclusión. De hecho el capítulo quinto de Lumen Gentium fue uno de los más discutidos y peleados dentro del aula. El motivo de esta polémica fue que no pocos padres conciliares preferían que el tema de la perfección cristiana fuese tratado junto al de la vida religiosa formando un solo capítulo. Esta era la visión tradicionalista como ya comentamos. Por el contrario, la nueva corriente que había nacido en los años previos al concilio y que se había gestado desde el siglo XIX a partir de las propuestas teológicas de la Escuela de Tubinga, proponía la separación entre "santidad" y"vida religiosa" constituyendo dos capítulos separados. Después de arduas negociaciones en la votación final se impuso la segunda propuesta de ahí que tengamos en el documento final de Lumen Gentium el capítulo quinto dedicado a la santidad universal y el sexto dedicado a la vida religiosa.

Además, en todo el texto se deja claro que el garante de toda santidad es Jesucristo ya que es a través de la gracia como el hombre puede llegar a la perfección cristiana. No son las propias fuerzas humanas las que hacen al hombre santo sino la participación en la vida de Cristo. El creyente, por su filiación recibida en el bautismo comienza a formar parte de la Iglesia, Cuerpo Místico de su Señor y en ella por medio de los sacramentos y de la acción del Espíritu que la anima consigue realizarse en el mandamiento de la caridad. ${ }^{34}$

A este respecto hay que reconocerle al concilio el que le haya afirmado al mundo entero que la santidad, que se manifiesta en la vivencia de los consejos evangélicos, no está reservada sólo y exclusivamente a unos pocos, es decir, a aquellos que se consagran a una vida religiosa, sino que es algo que está al alcance de todos los fieles con independencia de cuál sea su estado de vida.

Aquí vemos clarísimamente como el concilio adoptó una posición contraria a la propuesta en el De Ordine Morali que recordemos que mantenía la separación entre laicos y religiosos en relación a la santidad. Los primeros se deberían guiar por los preceptos de la ley natural concretados en los mandamientos por la Revelación (moral) y los segundos tendrían que orientarse según los consejos evangélicos (espiritualidad).

El Vaticano II supera esa polarización que durante siglos había marcado a la teología y al hacerlo da un paso más al cristificar la moral presentando a Jesucristo como modelo del comportamiento humano. Con esto los padres conciliares asumen nuevamente la línea de pensamiento que traía la Escuela de Tubinga. Ésta había incorporado en su reflexión teológica las aportaciones que desde la corriente personalista se venían presentando. Este movimiento filosó-

34 "In Lumen Gentium V, Cristo appare contemporáneamente come il maestro di ogni perfezione e soprattutto come l'autore e perfezionatore della santità nei credenti . Senza la sua grazia non è possibile per l'uomo riprodurre quanto egli ha compiuto. La realizzazione della santità, prima che una conquista umana, è una partecipazione alla vita divina comunicata dalla Chiesa. Gesù Salvatore arricchisce continuamente le membra del suo Corpo mistico mediante la sua divina Parola e i Sacramenti. Egli dona, poi, lo Spirito Santo affinchè muova interiormente l'uomo incitandolo a realizzare il comandamento della carità, compendio e vertice di tutta la Legge": M. DOLDI, Fondamenti cristologici...o.c., 48. 
fico sostenía que la personalidad ética de un individuo no se forjaba a partir de la obediencia fría a una ley sino en el seguimiento e imitación de un modelo. La teología moral desde el siglo XIX había comenzado a tener muy en cuenta esta afirmación de ahí que se empeñara en presentar a Cristo como modelo a seguir en el perfeccionamiento moral. ${ }^{35}$

A parte de la Lumen Gentium, entre el resto de los documentos que formaron parte del Concilio Vaticano II existe concretamente uno que ha servido para un posterior desarrollo de la teología moral. Nos referimos al número 16 de la Optatam Totius. El texto en cuestión es un decreto que trata sobre la formación sacerdotal. En él se hace un recorrido por las distintas disciplinas filosóficas y teológicas que forman parte del currículum académico de los candidatos a las órdenes sagradas. Lo interesante es que se cita de un modo explícito a nuestra disciplina y lo hace en estos términos: "Téngase especial cuidado en perfeccionar la teología moral, cuya exposición científica, nutrida con mayor intensidad por la doctrina de la Sagrada Escritura, deberá mostrar la excelencia de la vocación de los fieles en Cristo y su obligación de producir frutos en la caridad para la vida del mundo". ${ }^{36}$

Se trata de un texto breve pero denso pues en apenas una frase recoge toda la labor de renovación que desde san Alfonso María de Ligorio se venía haciendo para liberar a la moral de la casuística.

En un primer momento no se tenía la intención de aludir a la teología moral en el documento y mucho menos en los términos en los que se hace. De hecho en los esquemas precedentes de este decreto no se aludía a nuestra disciplina. Pero durante el período de discusión de los mismos algunos padres conciliares elevaron sus críticas a cómo se venía enseñando la moral dentro del seno de la Iglesia. El cardenal P. É. Léger, durante su intervención en la tercera sesión del concilio, que coincidió temporalmente con el período de discusión del esquema de la Optatam Totius, denunciaba el carácter marcadamente casuístico que tenía

35 "El divino Maestro y Modelo de toda perfección, el Señor Jesús, predicó a todos y cada uno de sus discípulos, cualquiera que fuese su condición, la santidad de vida, de la que Él es iniciador y consumador: Sed, pues, vosotros perfectos, como vuestro Padre celestial es perfecto (Mt 5,48). (...) Los seguidores de Cristo, llamados por Dios no en razón de sus obras, sino en virtud del designio y gracia divinos y justificados en el Señor Jesús, han sido hechos por el bautismo, sacramento de la fe, verdaderos hijos de Dios y partícipes de la divina naturaleza, y, por lo mismo, realmente santos. En consecuencia, es necesario que con la ayuda de Dios conserven y perfeccionen en su vida la santificación que recibieron. (...) Es, pues, completamente claro que todos los fieles, de cualquier estado o condición, están llamados a la plenitud de la vida cristiana y a la perfección de la caridad, y esta santidad suscita un nivel de vida más humano incluso en la sociedad terrena. En el logro de esa perfección empeñen los fieles las fuerzas recibidas según la medida de la donación de Cristo, a fin de que, siguiendo sus huellas y hechos conformes a su imagen, obedeciendo en todo a la voluntad del Padre, se entreguen con toda su alma a la gloria de Dios y al servicio del prójimo. Así, la santidad del Pueblo de Dios producirá abundantes frutos, como brillantemente lo demuestra la historia de la Iglesia con la vida de tantos santos": CONCILIO VATICANO II, Constitución dogmática sobre la Iglesia Lumen Gentium en loc. cit... n 40.

36 CONCILIO VATICANO II, Decreto sobre la formación sacerdotal Optatam Totius (28-octubre-1965), nº 16 en AAS 58 (1966). 
la teología moral la cual se había enclaustrado en un estricto legalismo, con lo que la hacía poco atractiva al hombre contemporáneo. Para Léger el problema básicamente se focalizaba en la fundamentación de la moral ya que una moral apoyada en la ley forzosamente tendrá que derivar en legalismo. Por ello él pidió expresamente en su intervención que se introdujese un párrafo en la Optatam Totius que hablara de la teología moral teniendo en cuenta cuatro cuestiones.

a) Que estuviese vinculada a la dogmática.

b) Que estuviera fundamentada en la Sagrada Escritura.

c) Que esté integrada en el Misterio de Cristo, es decir, que sea cristocéntrica.

d) Que su centro de interés no sea la ley sino la caridad.

El cardenal Léger no se encontraba solo en sus peticiones. Otros padres conciliares se unieron a sus reclamaciones como fue el caso de P.L. Seitz quien solicitaba en aula que la renovación de los estudios teológicos diera por terminado el largo período de separación entre la moral y la dogmática, algo que tanto daño había hecho tanto a una como a otra, aunque con más incidencia, si cabe, en la primera.

También fue importante la participación de otros obispos que en la línea de Léger y Seitz pedían con urgencia la renovación de nuestra disciplina. Este grupo de prelados solicitaba que se tuviese en cuenta en la renovación de la ética cristiana las aportaciones que otras ciencias como la psicología, la sociología, la antropología, la medicina, etc, pudiesen hacer no sólo para enriquecerla sino sobre todo para hacerla más cercana al hombre actual..$^{37}$

En definitiva, la redacción final el número 16 de la Optatam Totius había, finalmente, satisfecho las pretensiones y deseos de la mayoría de los obispos ya que, en primer lugar, se dotaba a la moral de un andamiaje antropológico apoyado en el misterio de Cristo, antropología que permitía concebir al hombre como hijo de Dios por la gracia en camino hacia la salvación en un continuo caminar en la imitación de su modelo que es Jesús el Señor. ${ }^{38}$ En segundo lugar, se conseguía introducir en la moral la Sagrada Escritura. Este fue el deseo del concilio no sólo para los estudios de moral sino para toda la teología en general, pues como bien establecía la constitución Dei Verbum aquélla debía constituir el alma de ésta. ${ }^{39}$ Ahora bien, el empleo

37 Cf. M. DOLDI, Fondamenti cristologici...o.c., 58.

38 "L'espresione 'illustrare l'altezza della vocazione dei fedeli in Cristo' enuncia la priorità data alla fondazione ontologica cristologica della morale (principio ontologico). L'in Cristo, finalmente, viene pienamente integrato nella morale cattolica, riconoscendo l'importanza del dato scritturistico in favore di un'antropologia 'della nuova creatura', di un'antropologia filiale d'incorporazione a Cristo e alla Chiesa mediante il battesimo e la fede": A.M. JERUMAIS, In Cristo...o.c., 370 .

39 "La teología se apoya, como en cimiento perdurable, en la Sagrada Escritura unida a la Tradición; así se mantiene firme y recobra su juventud, penetrando a la luz de la fe la verdad escondida en el misterio de Cristo. La Sagrada Escritura contiene la palabra de Dios y en cuanto inspirada es realmente palabra de Dios; por eso la Escritura debe ser alma de la teología. El misterio de la palabra, que incluye la predicación pastoral, la catequesis, toda la instrucción cristiana y en 
de la Escritura en la moral no sería ya más como se utilizó en los años anteriores que consistía en buscar en la Biblia algunas citas que confirmaran los postulados éticos ya previamente establecidos. Ni tampoco consistiría en extrapolar los códigos éticos presentes tanto en el Antiguo como en el Nuevo Testamento para aplicárselos al hombre contemporáneo. ${ }^{40}$ Lo que se pretende a partir de este momento de renovación es profundizar en la exégesis para averiguar la verdad moral contenida en la Biblia para depurarla de las adherencias culturales en las que están insertas. Lo que hay que presentarle al hombre de hoy es esa verdad inmutable, no la forma en la que ésta se expresa que pertenece a una cultura concreta. Además, con este basamento escriturístico la teología moral tiene ante sí el camino allanado para vincularse a la dogmática, deseo generalizado entre los padres conciliares.

En conclusión, el documento De Ordine Morali no respondía a las exigencias y pretensiones de un concilio que quería abrir las puertas de la Iglesia al mundo. Su lenguaje era abstracto, su contenido impersonal y su método estático y, aunque se intentó su reestructuración, ninguna mejora convenció a nadie. La opción por su eliminación pareció lo más conveniente dadas las circunstancias que rodearon a los padres conciliares. Pero el hecho de que no exista ningún documento en elVaticano II dedicado a la moral no debe llevar a nadie a pensar que ésta se encuentre ausente pues, como ya hemos explicado, las líneas de renovación que experimentó nuestra disciplina desde hacía más de un siglo, fueron asumidas por los obispos y peritos participantes del evento eclesial más importante del pasado siglo.

\subsection{El período postconciliar}

Todo apuntaba a que después del concilio la teología moral logaría alcanzar una sistematización sólida y uniforme en su renovación ya que el concilio había establecido las líneas a seguir por los moralistas. Sin embargo, no fue eso lo que

puesto privilegiado la homilía, recibe de la palabra de la Escritura alimento saludable y por ella da frutos de santidad": CONCILIOVATICANO II, Constitución dogmática sobre la Divina Revelación Dei Verbum (18-noviembre-1965), n 24 en AAS 58 (1966).

40 La Pontificia Comisión Bíblica se inserta en esta misma línea y a este respecto se pronuncia en los siguientes términos: "Nella Bibbia si trovano molte norme, comandamenti, leggi, raccolte di codici, ecc. Una attenta lettura fa rilevare, però, che tali norme non sono mai isolate, a sé stanti, bensì appartengono sempre a un determinato contesto. Si può dire che nell'antropologia bíblica ciò che è primario e fondamentale è l'agire de Dio, che previene quello dell'uomo, i suoi doni di grazia, il suo invito alla comunione: il complesso normativo è una conseguenza per indicare all'uomo quale sia il modo adeguato di accogliere il dono di Dio e di viverlo. Alla base di questa concezione biblica c'è la visione della persona umana così como è stata creata da Dio: essa non è mai un essere isolato, autonomo, svincolato da tutto a da tutti, ma si trova in un rapporto radicale e essenziale con Dio e con la comunità dei fratelli. Dio ha creato l'uomo secondo la propia immagine: la stessa esistenza dell'uomo è il primo e fondamentale dono che egli ha ricevuto da Dio. Nella prospettiva biblica un discorso sulle norme morali non può essere ristretto ad ese, prese in maniera isolata, ma debe essere sempre inserito nel contesto della visione biblica dell'esistenza umana": PONTIFICIA COMMISSIONE BIBLICA, Bibbia e Morale. Radici bibliche dell'agire cristiano, Libreria Editrice Vaticana, Città del Vaticano, 2008, 7. 
ocurrió. De hecho podríamos decir que la disciplina teológica más controvertida en la etapa postconciliar fue precisamente la moral hasta el punto de que se podría afirmar que fracasó por completo en su intento por incluir las directrices dadas para nuestra disciplina en las aulas sinodales.

Algunos estudiosos del tema como Aurelio Fernández han intentado explicar el porqué de esa situación:

"Las razones de este fracaso fueron, entre otras, las tres siguientes: el afán excesivo de reforma en unos, el tradicionalismo exagerado en otros y -posiblemente en todos- la falta del rigor intelectual debido. Cuando se haga la historia de las ideas morales de esa época no dejará de sorprender la ligereza con que se rompe con el pensamiento anterior, de forma que la novedad parecía ser el único aval de veracidad. Esa misma actitud muestra que más que el rigor interesa lo original. Así lo 'nuevo' sustituye a lo 'verdadero'. Pero ese afán desmedido por el 'cambio' reafirmó en otros la repulsa a toda reforma, y en su 'conservadurismo', incluso rechazaban aquellos elementos que había destacado el Concilio. El hecho es que aquella gran esperanza se vio frustrada, pues la literatura teológico-moral inmediata posconciliar acusa muy pronto graves desviaciones. No es fácil entender cómo algunos autores de cierto fuste intelectual se venden a tendencias de tan poco rigor científico. También (...) da la impresión de que las enseñanzas del Concilio Vaticano II, en vez de madurez intelectual, en algunos sólo despertó el deseo innovador y en otros provocó una especie de convulsionada pubertad de espíritu." ${ }^{41}$

Efectivamente, el clima de renovación que se generó en los años inmediatamente después del concilio llevó a no pocos moralistas a confundir lo nuevo con lo verdadero. Se trataba de teólogos que se dejaron seducir por las voces de una sociedad que pedía a la Iglesia un cambio en sus directrices éticas, como si la verdad moral que ha sido revelada pudiese ser cambiada. Por eso no debe extrañarnos que la misma noción de ley natural fuese atacada, o cuanto menos ignorada, por aquellos que deberían haberla protegido en medio de una cultura cada vez más plural y heterogénea. Sin embargo, amparándose en el deseo del concilio de liberar a la moral del positivismo jurídico de los siglos anteriores optaron también por la negación de una ley que obligue siempre y en todo lugar bajo pena de pecado. Precisamente este fenómeno dio cabida en el seno de la teología moral a la aparición de las llamadas éticas de situación que dieron paso a la introducción del subjetivismo y del relativismo moral en la teología.

El panorama posconciliar de nuestra disciplina no fue muy halagüeño debido a las graves desviaciones que se produjeron al introducirse en el contexto de la moral de situación a la que hemos aludido las éticas teleológicas y circunstancialistas. Para entender esto tenemos que remitirnos a las fuentes de la moralidad. Para nuestra ciencia existen tres elementos indispensables para poder

41 A. FERNÁNDEZ, La reforma de la Teología Moral. Medio siglo de historia, Ediciones Aldecoa, Burgos, 1997, 111-112. 
emitir una valoración moral acerca de una acción. Estos tres elementos son el objeto, el fin y las circunstancias. Si en los años previos al concilio los moralistas ponían el acento en el primero de ellos, después del concilio se comenzó a sobrevalorar los otros dos en detrimento de aquél.

Aquellos autores que decidieron hacer hincapié en el fin dieron con ello a la aparición de las éticas finalistas, conocidas también como teleológicas. De entre ellas, las dos más conocidas son el consecuencialismo y el proporcionalismo. Si la primera hace derivar su juicio moral de las consecuencias que se extraigan de la acción del sujeto agente, la segunda lo hará de la relación de proporcionalidad entre los efectos buenos y los efectos malos que de dicha acción se deriven.

Por su parte, los autores que se centran en las circunstancias para la emisión de sus juicios dieron con ello inicio al denominado circunstancialismo ético, es decir, una acción será buena o mala dependiendo de las circunstancias que rodeen a la persona que actúa.

Ante este contexto teológico no debe extrañarnos que desde ciertos sectores se cuestionara muchos pronunciamientos oficiales del Magisterio. El caso paradigmático lo tenemos con la encíclica Humanae Vitae del papa PabloVI que suscitó no pocas polémicas entre los moralistas. ${ }^{42}$

Estas desviaciones en el campo de la moral fueron corregidas de manera magistral por el papa Juan Pablo II con la encíclica Veritatis Splendor donde se condenan de modo expreso estas corrientes de la"nueva ética" ${ }^{43}$

En resumen, podemos decir que la etapa posconciliar no fue como se esperaba. El camino de renovación que abrió la Escuela de Tubinga mereció una conclusión más honrosa por parte de los moralistas posconciliares. Es cierto que lo conseguido hasta el Vaticano II, entiéndase una teología moral vinculada a la dogmática, que tenga la caridad por ley y centrada en el misterio de Cristo sigue estando presente en los planteamientos de los grandes moralistas católicos. Pero hay que seguir trabajando para integrar todo eso con una noción de ley natural que garantice la permanencia de normas morales objetivas que son válidas para todos los hombres y para todas las épocas. La lectura de las acciones llevada a cabo por la corriente historicista radical no siempre ha tenido esto en cuenta. No negamos el valor de los contextos históricos en los que actuamos, pero esto no debe implicar la negación de una verdad moral que no se deja modificar por el paso del tiempo. Mucho es lo que se ha conseguido en este último siglo y medio de estudio y mucho es también lo que le debemos a aquellos moralistas que desde san Alfonso María de Ligorio se han afanado por presentar una ciencia moral que tenga como finalidad llevar al hombre a Dios. Ojalá que

42 Ibid. 119-127.

43 Para un acercamiento al litigio de esta encíclica con las nuevas corrientes nacidas a la luz del posconcilio, cf. A. BONANDI, Veritatis Splendor. Treinta años de Teología Moral, Cristiandad, Madrid, 2003; J.A. SAYÉS, Antropología y moral. De la "nueva moral" a la Veritatis Splendor, Palabra, Madrid, 1997. 
los moralistas del siglo XXI podamos seguir con la línea marcada de renovación sin salirnos del dato revelado custodiado por la Iglesia a través de su Magisterio.

\section{CONCLUSIÓN}

En este recorrido histórico que hemos presentado sobre la renovación de nuestra disciplina hemos podido ver cuáles han sido los errores fundamentales que se han llevado a cabo. Desencarnar la teología moral de la antropología lleva a la ética cristiana a una dimensión de abstracción que no llega a decir nada al hombre de cualquier cultura. Desencarnarla de la dogmática la lleva a perder de vista el horizonte soteriológico y por consiguiente, de su fin último que es Dios mismo. Hacer lo propio con respecto a la ascética conduce a reducirla a pura normatividad para llegar al mínimo ético exigido para no pecar.Y desvincularla de la Sagrada Escritura nos lleva a situarnos ante una disciplina vacía de contenido y sin alma.

Es mucho lo que se ha conseguido hasta elVaticano II. No obstante, los años posteriores al concilio fueron tan convulsos que en ciertos sectores eclesiales la simple noción de renovación en el ámbito de la moral suena ya a desviación doctrinal. Quienes así piensan lo hacen motivado por las afirmaciones y planteamientos que desde el proporcionalismo, el consecuencialismo y el circunstancialismo se han propuesto. Ciertamente hay motivos para la preocupación puesto que con ello se ha sembrado la semilla del relativismo y del subjetivismo. Pero esto no debe llevarnos a inferir que todo intento de renovación teologal desemboque siempre en una concepción heterodoxa.

Los nuevos planteamientos y las nuevas propuestas de acción teológicas si se hacen con sentido común, con sentido de la responsabilidad pastoral y sobre todo con fidelidad a la Revelación (Sagrada Escritura y Sagrada Tradición) en comunión con el Magisterio de la Iglesia que es quien tiene la misión de salvaguardarla, pueden ser muy beneficiosas para seguir profundizando en el misterio delVerbo Encarnado. No creemos que la teología moral deba renunciar a seguir renovándose. Lo que tiene que hacer es renunciar a hacerlo fuera de los límites establecidos para ello. La prueba de que esto es posible lo tenemos en San Alfonso María de Ligorio, con quien se inicia de un modo más sistemático la renovación cristológica de la moral y que ha sido declarado santo y patrón de todos los moralistas por nuestra madre la Iglesia. 